\title{
Anurofauna do noroeste paulista: lista de espécies e chave de identificação para adultos
}

\author{
Diogo Borges Provete ${ }^{1,2,3,5}$, Michel Varajão Garey ${ }^{1,2}$, \\ Fernando Rodrigues da Silva ${ }^{1,2,4}$ \& Denise de Cerqueira Rossa-Feres ${ }^{1}$ \\ ${ }^{1}$ Laboratório de Ecologia Animal, Departamento de Zoologia e Botânica, Instituto de Biociências, Letras \\ e Ciências Exatas, Universidade Estadual Paulista - UNESP, R. Cristóvão Colombo, 2265, Jd. Nazareth, \\ CEP 15054-000, São José do Rio Preto, SP, Brasil \\ ${ }^{2}$ Programa de Pós-graduação em Biologia Animal, Departamento de Zoologia e Botânica, Instituto de \\ Biociências, Letras e Ciências exatas, Universidade Estadual Paulista - UNESP, R. Cristóvão Colombo, \\ 2265, Jd. Nazareth, CEP 15054-000, São José do Rio Preto, SP, Brasil, e-mail: michelgarey@gmail.com; \\ bigosbio@yahoo.com.br; denise@ibilce.unesp.br \\ ${ }^{3}$ Programa de Pós-Graduação em Ecologia e Evolução, Laboratório de Ecologia de Insetos, \\ Departamento de Ecologia, Instituto de Ciências Biológicas, \\ Universidade Federal de Goiás - UFG, CP 131, CEP 74001-970, Goiânia, GO, Brasil \\ ${ }^{4}$ Universidade Federal de São Carlos - UFSCAR, Campus Sorocaba, \\ Rod. João Leme dos Santos Km 110, CEP 18052-780, Sorocaba, SP, Brasil \\ ${ }^{5}$ Autor para correspondência: Diogo Borges Provete, e-mail: dbprovete@gmail.com
}

PROVETE, D.B., GAREY, M.V., SILVA, F.R. \& ROSSA-FERES, D.C. Anuranfauna from northwestern region of the State of São Paulo: species list and taxonomic key for adults. Biota Neotrop. 11(2): http://www. biotaneotropica.org.br/v11n2/en/abstract?identification-key+bn01111022011.

\begin{abstract}
The correct identification of species is a common impediment for studies of conservation, management and environmental licensing. Currently, 37 species from five families of anuran amphibians are recorded in the region that includes the Turvo-Grande, São José dos Dourados and parts of the Low Pardo, Low Tietê and Tietê-Batalha Hydric Resources Management Unit (UGRHIs). Despite of being studied since de mid-1960's, none identification key that included all the species recognized was available. Although developed for a regional anuranfauna, this key has wide application because the species found in the studied region are associated to open areas and have wide geographical distribution. This study aims to fill this gap presenting an illustrated list about species' biology, and a dichotomous key that comprises 37 anuran species.
\end{abstract}

Keywords: identification key, amphibians, biodiversity inventory, habitat use, reproductive modes, seasonal occurrence.

PROVETE, D.B., GAREY, M.V., SILVA, F.R. \& ROSSA-FERES, D.C. Anurofauna do noroeste paulista: lista de espécies e chave de identificação para adultos. Biota Neotrop. 11(2): http://www.biotaneotropica.org.br/ v11n2/pt/abstract?identification-key+bn01111022011.

Resumo: A correta identificação de espécies normalmente é um obstáculo para estudos de conservação, manejo e licenciamento ambiental. Atualmente 37 espécies de cinco famílias de anfíbios anuros são registradas na área que abrange integralmente as Unidades de Gerenciamento dos Recursos Hídricos (UGRHIs) do Turvo-Grande e São José dos Dourados e parte das UGHRIs do Baixo Pardo, Baixo Tietê e Tietê-Batalha. Embora esta fauna venha sendo objeto de estudos quase ininterruptos desde a metade da década de 1960, nenhuma chave de identificação que incluísse todas as espécies reconhecidas na região estava disponível. Embora desenvolvida para uma anurofauna regional, esta chave tem ampla aplicação porque as espécies encontradas na área de abrangência do estudo são associadas à áreas abertas e apresentam ampla distribuição geográfica. Este estudo visa preencher esta lacuna e apresentar uma lista ilustrada e uma chave dicotômica artificial para as 37 espécies de anuros conhecidas para esta região.

Palavras-chave: chave dicotômica, anfíbios, inventário de biodiversidade, uso de hábitat, modos reprodutivos, ocorrência sazonal. 


\section{Introdução}

O Brasil abriga a maior diversidade de anfíbios do planeta com 875 espécies, sendo registradas 847 espécies de anuros (Sociedade... 2010), das quais 230 são conhecidas para o Estado de São Paulo (Araújo et al. 2009, Rossa-Feres et. al. 2011). Por concentrar vários centros de pesquisa, o Estado de São Paulo é a região brasileira onde os anuros têm sido mais estudados, mas ainda existem grandes lacunas no conhecimento sobre as espécies deste Estado (Rossa-Feres et al. 2008, Araújo et al. 2009, Rossa-Feres et al. 2011).

Para a região noroeste do Estado de São Paulo são conhecidas 37 espécies de anuros, o que representa 4,36\% do total de espécies brasileiras e 16,09\% do estado (Vizotto 1967, Cais 1992, Bernarde \& Kokubum 1999, Vasconcelos \& Rossa-Feres 2005, Santos et al. 2007, Prado et al. 2008, Silva et al. 2009, Prado 2009, Silva et al. 2010). A anurofauna dessa região é composta, em sua maioria, por espécies características de ambientes de formação vegetal aberta (Duellman 1999, Santos et al. 2009), sendo que a maior riqueza de espécies é registrada em corpos d'água lênticos e temporários (Rossa-Feres \& Jim 2001, Vasconcelos \& Rossa-Feres 2005, Santos et al. 2007).

A formação vegetal dessa região, originalmente constituída por Floresta Estacional Semidecidual e Cerrado (Ab'Saber 2003), foi intensamente modificada desde o século XIX, sendo substituída por pastagens, culturas diversas e áreas urbanas, restando atualmente apenas 9\% de sua área original (Kronka et al. 1993). Recentemente, o cultivo de cana-de-açúcar vem se expandindo rapidamente na região (Rudorff et al. 2004), aumentando ainda mais a taxa de desmatamento, pela remoção parcial ou completa de fragmentos florestais remanescentes (Silveira 2002). Hoje, esta região é a mais desmatada e fragmentada do Estado e prioritária para inventários de fauna e flora, tanto pelo desconhecimento biológico, quanto pela raridade de fragmentos de Floresta Estacional Semidecidual de bom tamanho (Rodrigues et al. 2008). Tal cenário, associado à menor concentração de unidades de conservação, compõe um quadro de degradação ambiental que aparentemente não será revertido sem ações de manejo do meio ambiente (Kronka et al. 1993). Apesar do impacto da mudança de uso de solo no noroeste paulista, quatro novos registros de espécies de anfíbios anuros foram feitos nos últimos anos: Chiasmocleis albopunctata (Silva et al. 2009), Dendropsophus melanargyreus (Silva et al. 2010), Phyllomedusa azurea (Prado et al. 2008) e Hypsiboas faber (Prado 2009). Estes registros foram obtidos nos recentes inventários realizados na região no âmbito do projeto "Fauna e flora de fragmentos florestais remanescentes no noroeste paulista: bases para estudos de conservação da biodiversidade" (BIOTA/FAPESP).

Apesar da anurofauna dessa região ser objeto de estudos desde a década de 60 (Vizotto 1967), apenas uma chave de identificação para os girinos de 22 espécies de anuros está disponível (Rossa-Feres \& Nomura 2006). Neste estudo apresentamos uma chave dicotômica e uma lista ilustrada para as 37 espécies de anuros registradas na região noroeste do estado de São Paulo. Nesse sentido, esperamos contribuir com uma ferramenta rápida para a identificação das espécies, não só para estudos ecológicos, mas também para eventuais inventários da anurofauna voltados para o licenciamento ambiental e a conservação dos anfíbios anuros dessa região.

\section{Material e Métodos}

Para elaboração deste trabalho, adotaremos como sendo os limites da região noroeste do Estado de São Paulo as áreas que abrangem integralmente as Unidades de Gerenciamento dos Recursos Hídricos
(UGRHIs) do Turvo-Grande e São José dos Dourados e partes das UGHRIs do Baixo Pardo, Baixo Tietê e Tietê-Batalha (Figura 1).

O comprimento rostro-cloacal (CRC) foi determinado com paquímetro em ao menos 10 exemplares de cada espécie. As espécies foram classificadas em três grupos com relação ao tamanho corporal: 1) pequeno porte, inferior a $29 \mathrm{~mm}$; 2) médio porte, 30 a $79 \mathrm{~mm}$; e 3) porte grande, acima de $80 \mathrm{~mm}$. Os dados biológicos de ocorrência temporal, hábitat, sítio de vocalização e de desova das espécies foram compilados de estudos desenvolvidos na região noroeste do Estado de São Paulo (e.g., Cais 1992, Nomura 2003, Santos et al. 2007, Silva et al. 2008, Vasconcelos \& Rossa-Feres 2008, Prado 2009, Silva et al. 2010). A classificação dos modos reprodutivos segue Haddad \& Prado (2005).

A nomenclatura das espécies foi considerada de acordo com Frost (2010). Os exemplares examinados para a elaboração dessa chave estão depositados na Coleção DZSJRP - Amphibia, do Departamento de Zoologia e Botânica da UNESP, campus de São José de Rio Preto, São Paulo, cuja base de dados está disponível no site do SpeciesLink (2010).

\section{Resultados e Discussão}

\section{Biologia das espécies}

Dentre todas as espécies de anuros consideradas neste estudo (Figura 2), seis (16,21\%) são consideradas de grande porte, 23 espécies $(62,16 \%)$ tem porte médio, e oito espécies $(21,62 \%)$ tem pequeno porte (Figura 3). A maioria (88\%) das espécies apresenta distribuição temporal restrita à estação chuvosa (Figura 4). A estação seca na região é muito pronunciada, recebendo apenas $15 \%$ do volume anual de precipitação pluviométrica, que varia de 1.100 a $1.250 \mathrm{~mm}( \pm 225$ $\mathrm{mm}$ ), sendo as chuvas concentradas entre outubro e março (Barcha \& Arid 1971, Santos et al. 2007). Além disso, o mês de início da estação chuvosa varia a cada ano e as chuvas são inconstantes, não impedindo que os corpos d'água temporários sequem uma ou duas vezes após as primeiras chuvas (Rossa-Feres \& Jim 2001). Esta condição climática associada com a baixa complexidade estrutural dos corpos d'água (Santos \& Rossa-Feres 2007, Vasconcelos \& Rossa-Feres 2008), pode explicar diversos parâmetros das comunidades de anuros na região, tais como a baixa riqueza de espécies (Santos et al. 2007, Vasconcelos et al. 2010), o pequeno número de modos reprodutivos (Vasconcelos et al. 2010), e a grande sobreposição na utilização de sítios de vocalização (Rossa-Feres \& Jim 2001, Vasconcelos \& Rossa-Feres 2005, Santos et al. 2007, Silva et al. 2008).

Ao todo são registrados seis modos reprodutivos na região (15\% do total conhecido; Haddad \& Prado 2005). As espécies que ocorrem na região exibem modos reprodutivos que são generalizados (modos 1, 2 e 4) ou adaptados à dessecação (modos 11, 13 e 30) (Figura 5). Este padrão pode ser atribuído à predominância de espécies típicas de áreas abertas, com a exceção de Hypsiboas lundii e Leptodactylus mystaceus, que são encontradas na borda ou no interior de fragmentos (Silva \& Rossa-Feres 2007) (Figura 6). Além disso, poucas espécies com modos reprodutivos especializados são encontradas em hábitats secos e/ou altamente sazonais (Duellman \& Trueb 1986), pois são preponderantemente dependentes de ambientes com alta umidade e previsibilidade de precipitação (Duellman \& Trueb 1986, Haddad \& Prado 2005).

A grande sobreposição no uso de sítio de vocalização entre as espécies (Rossa-Feres \& Jim 2001, Santos \& Rossa-Feres 2007, Vasconcelos \& Rossa-Feres 2008), pode ser explicada pela baixa complexidade estrutural dos corpos d'água, decorrente da 


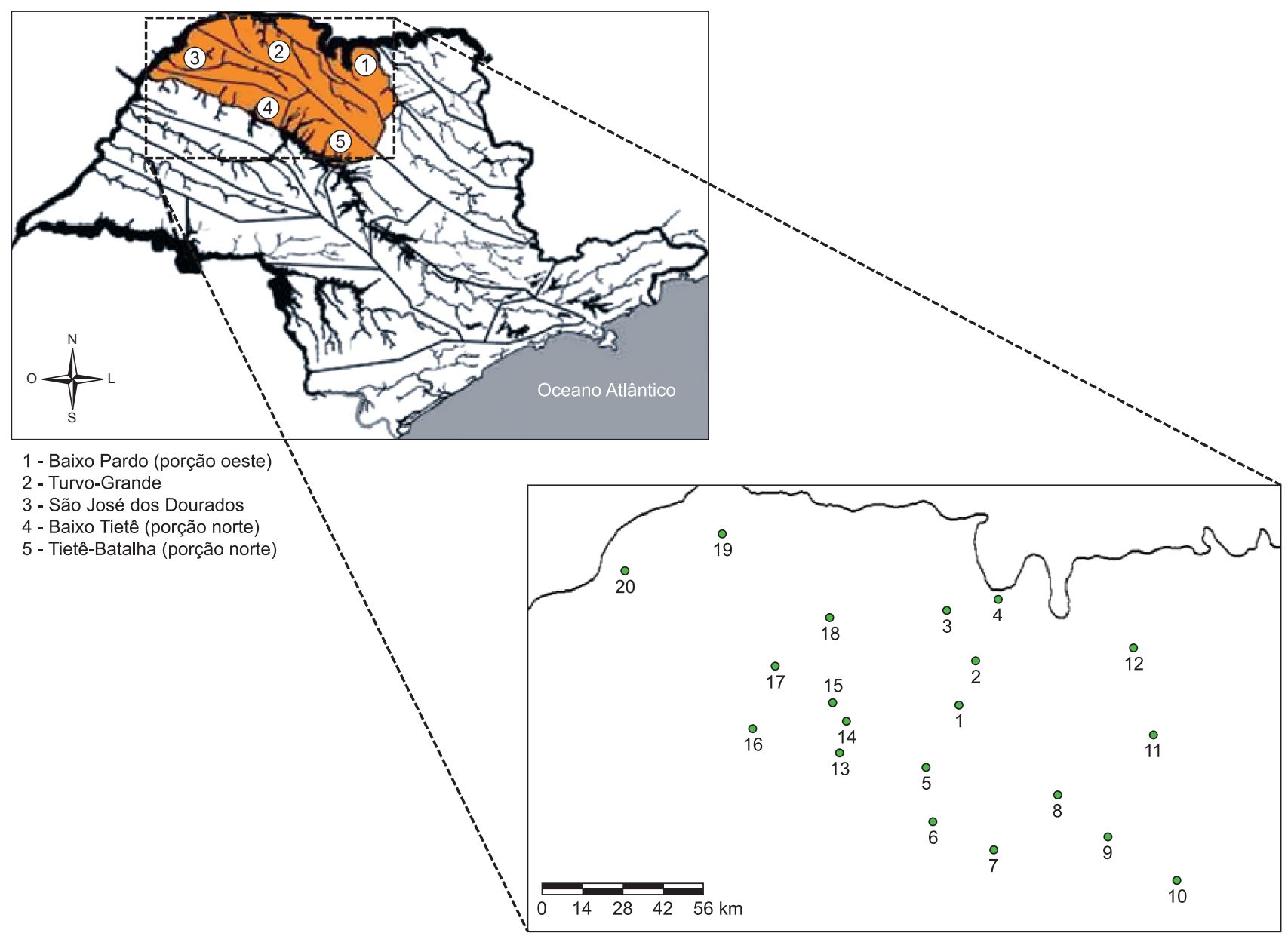

Figura 1. Mapa com os limites da região noroeste do Estado de São Paulo, conforme definida neste estudo (em laranja), destacando as Unidades de Gerenciamento de Recursos Hídricos (círculos brancos). Em destaque, 20 municípios (círculos verdes) onde foram realizados levantamentos de anuros. 1) São José do Rio Preto; 2) Onda Verde; 3) Palestina; 4) Icém; 5) Nova Itapirema; 6) Sales; 7) Novo Horizonte; 8) Pindorama; 9) Taquaritinga; 10) Matão; 11) Bebedouro; 12) Barretos; 13) Planalto; 14) União Paulista; 15) Macaubal; 16) Vicentinópolis; 17) Magda; 18) Votuporanga; 19) Turmalina; e 20) Santa Fé do Sul.

Figure 1. Map showing the northwest region of the state of São Paulo, as defined in this study (in orange). Numbers refer to the Unidades de Gerenciamento de Recursos Hídricos (white circles). The inset shows 20 counties (green circles) where anuran surveys were carried out. 1) São José do Rio Preto; 2) Onda Verde; 3) Palestina; 4) Icém; 5) Nova Itapirema; 6) Sales; 7) Novo Horizonte; 8) Pindorama; 9) Taquaritinga; 10) Matão; 11) Bebedouro; 12) Barretos; 13) Planalto; 14) União Paulista; 15) Macaubal; 16) Vicentinópolis; 17) Magda; 18) Votuporanga; 19) Turmalina; and 20) Santa Fé do Sul.

predominância de vegetação herbácea na região marginal, resultado da intensa atividade agrícola na região (Rossa-Feres \& Jim 2001, Santos et al. 2007, Vasconcelos \& Rossa-Feres 2008).

\section{Comentários taxonômicos}

Assim como para outras espécies encontradas no Estado de São Paulo (Araújo et al. 2009), várias espécies e gêneros registrados na região noroeste necessitam de revisão taxonômica. Por exemplo, comparações com material de coleções científicas e análises citogenéticas indicam que três das quatro espécies de Pseudopaludicola registradas no noroeste paulista são provavelmente espécies ainda não descritas: Pseudopaludicola sp. (aff. mystacalis) compartilha o mesmo número cromossômico (Fávero et al. in press) com $P$. mystacalis, mas difere desta espécie pelos maiores porte e largura da cabeça; Pseudopaludicola sp. (aff. falcipes I) é provavelmente uma nova espécie semelhante à $P$. falcipes, da qual difere morfologicamente e no número cromossômico [2n = 16 em
Pseudopaludicola sp. (aff. falcipes I) e $2 n=22$ em $P$. falcipes; Fávero et al. in press]; Pseudopaludicola sp. (aff. falcipes II) é uma nova espécie semelhante à $P$. canga, com a qual compartilha o mesmo número cromossômico $(2 \mathrm{n}=18)$ (Duarte et al. 2010), mas difere pelo menor porte, corpo mais esguio e cabeça mais estreita.

Scinax sp. (aff. similis) também necessita de revisão para confirmar seu status taxonômico. Os indivíduos adultos das populações encontradas na região amostrada são morfologicamente semelhantes a $S$. similis, mas seus girinos diferem em várias características (Rossa-Feres \& Nomura 2006) do girino descrito para essa espécie proveniente da localidade tipo, município do Rio de Janeiro (Alves \& Carvalho-e-Silva 1999).

Leptodactylus latrans (antigo L. ocellatus) (Lavilla et al. 2010) pode representar um complexo de espécies, pois a associação de um topótipo a uma localidade-tipo é crítica para as espécies de Leptodactylus (de Sá et al. 2007), e é provável que existam populações de espécies diferentes sendo tratadas como L. latrans. 

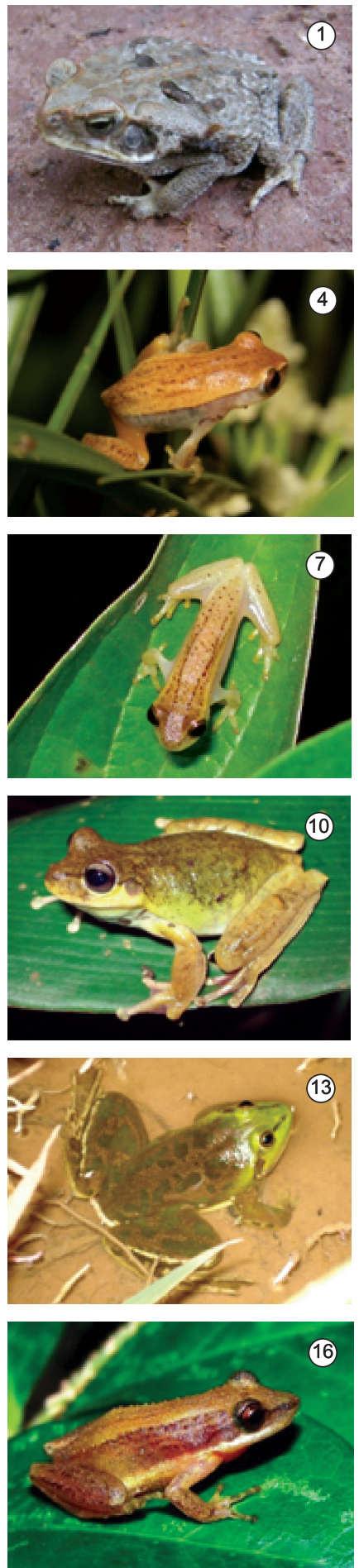
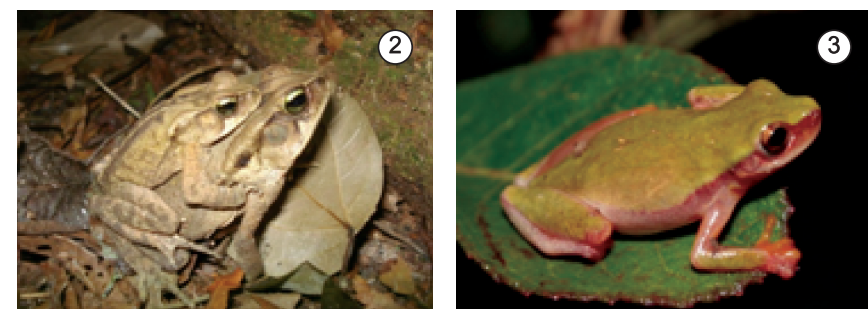

(5)
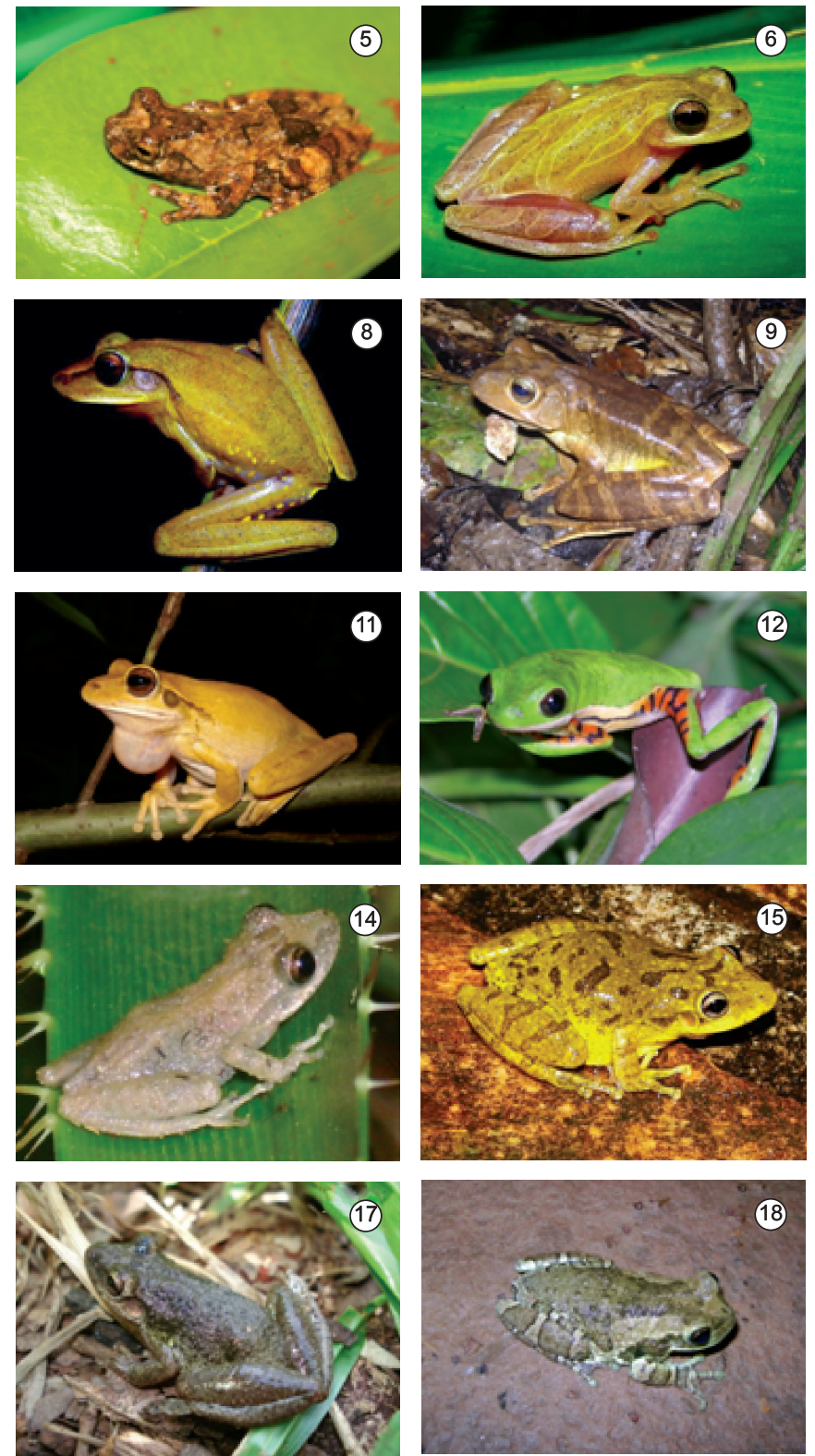

Figura 2. Espécies de anuros registrados na região noroeste do estado de São Paulo. 1) Rhinella schneideri; 2) Rhinella ornata; 3) Dendropsophus elianeae; 4) Dendropsophus nanus; 5) Dendropsophus melanargyreus; 6) Dendropsophus minutus; 7) Dendropsophus sanborni; 8) Hypsiboas albopunctatus; 9) Hypsiboas faber; 10) Hypsiboas lundii; 11) Hypsiboas raniceps; 12) Phyllomedusa azurea; 13) Pseudis platensis; 14) Scinax berthae; 15) Scinax fuscovarius; 16) Scinax fuscomarginatus; 17) Scinax sp. (aff. similis); 18) Trachycephalus typhonius.

Figure 2. Anuran species recorded in the northwestern region of São Paulo. 1) Rhinella schneideri; 2) Rhinella ornata; 3) Dendropsophus elianeae; 4) Dendropsophus nanus; 5) Dendropsophus melanargyreus; 6) Dendropsophus minutus; 7) Dendropsophus sanborni; 8) Hypsiboas albopunctatus; 9) Hypsiboas faber; 10) Hypsiboas lundii; 11) Hypsiboas raniceps; 12) Phyllomedusa azurea; 13) Pseudis platensis; 14) Scinax berthae; 15) Scinax fuscovarius; 16) Scinax fuscomarginatus; 17) Scinax sp. (aff. similis); 18) Trachycephalus typhonius. 

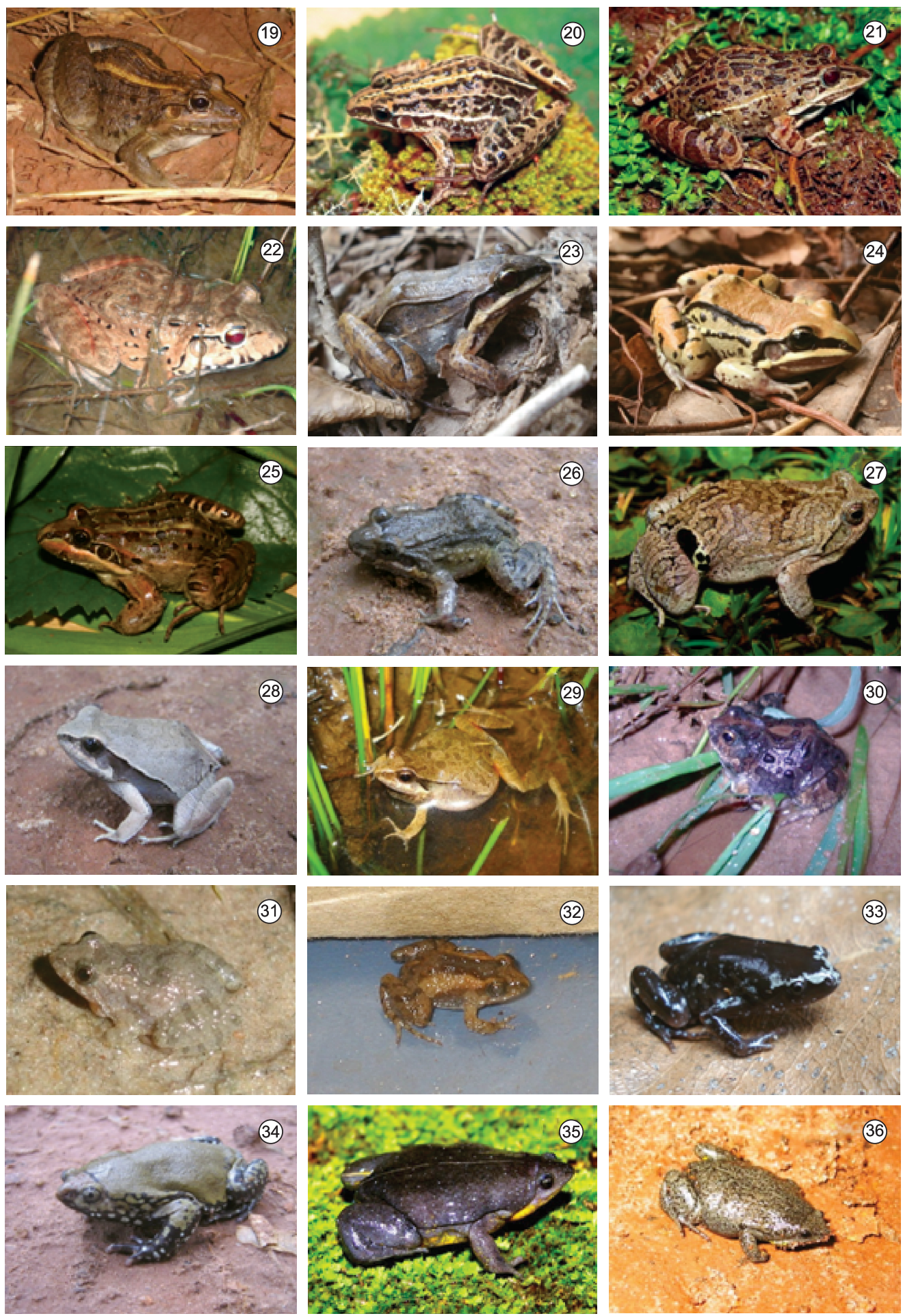

Figura 2. Espécies de anuros registrados na região noroeste do estado de São Paulo. 19) Leptodactylus chaquensis; 20) Leptodactylus furnarius; 21) Leptodactylus fuscus; 22) Leptodactylus labyrinthicus; 23) Leptodactylus mystaceus; 24) Leptodactylus mystacinus; 25) Leptodactylus latrans; 26) Leptodactylus podicipinus; 27) Eupemphix nattereri; 28) Physalaemus centralis; 29) Physalaemus cuvieri; 30) Physalaemus marmoratus; 31) Pseudopaludicola sp. (aff. falcipes I); 32) Pseudopaludicola mystacalis; 33) Chiasmocleis albopuncata; 34) Dermatonotus muelleri; 35) Elachistocleis bicolor; 36) Elachistocleis cesarii.

Figura 2. Anuran species recorded in the northwestern region of São Paulo. 19) Leptodactylus chaquensis; 20) Leptodactylus furnarius; 21) Leptodactylus fuscus; 22) Leptodactylus labyrinthicus; 23) Leptodactylus mystaceus; 24) Leptodactylus mystacinus; 25) Leptodactylus latrans; 26) Leptodactylus podicipinus; 27) Eupemphix nattereri; 28) Physalaemus centralis; 29) Physalaemus cuvieri; 30) Physalaemus marmoratus; 31) Pseudopaludicola sp. (aff. falcipes I); 32) Pseudopaludicola mystacalis; 33) Chiasmocleis albopuncata; 34) Dermatonotus muelleri; 35) Elachistocleis bicolor; 36) Elachistocleis cesarii. 


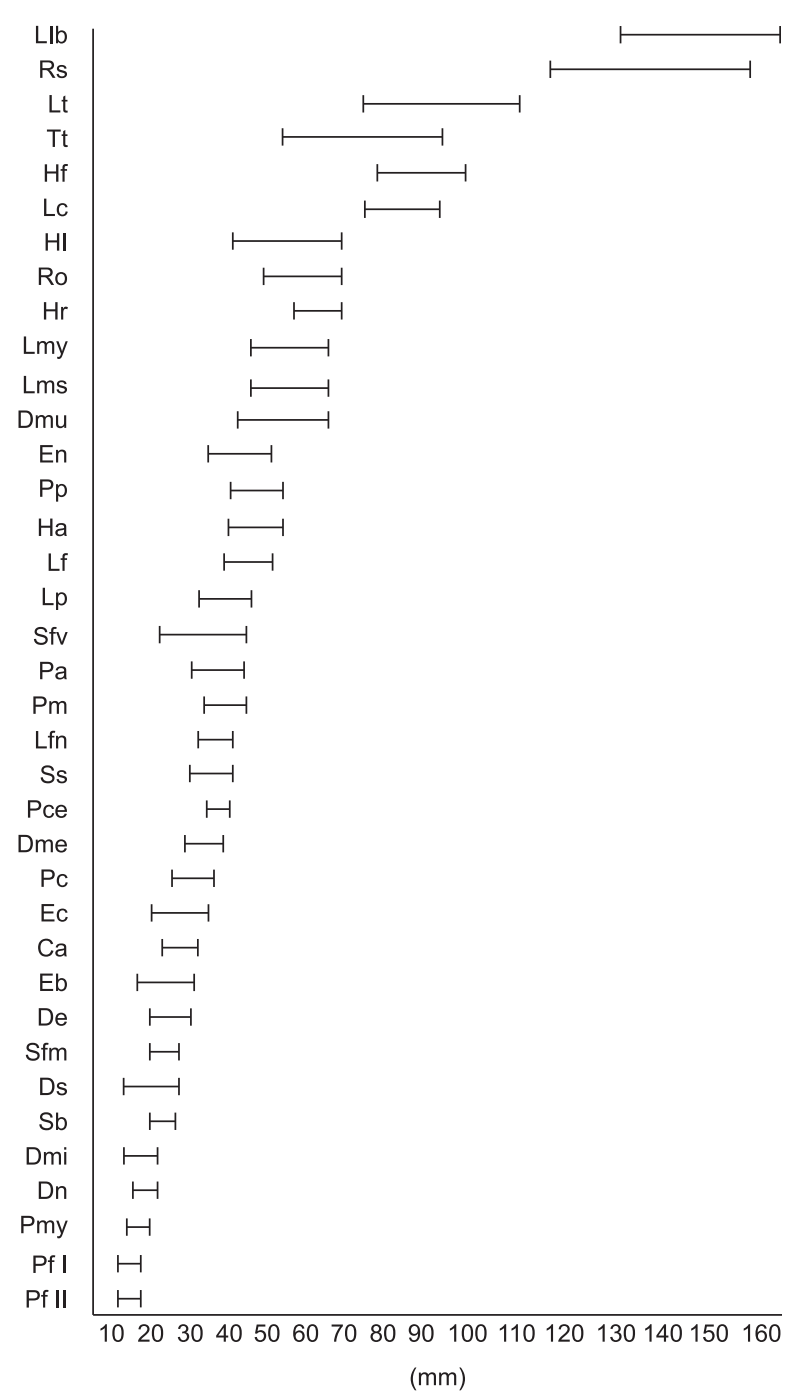

Figura 3. Comprimento rostro-cloacal (CRC) das espécies de anuros registradas na região noroeste do estado de São Paulo. Rs) Rhinella schneideri; Hf) Hypsiboas faber; Tt) Trachycephalus typhonius; Hl) H. lundii; Ro) R. ornata; Hr) H. raniceps; Pp) Pseudis plantensis; Ha) H. albopunctatus; Sfv) Scinax fuscovarius; Pa) Phyllomedusa azurea; Ss) S. sp. (aff. similis); Dme) Dendropsophus melanargyreus; De) D. elianeae; Sfm) S. fuscomarginatus; Ds) D. sanborni; Sb) S. berthae; Dmi) D. minutus; Dn) D. nanus. Llb) Leptodactylus labyrinthicus; Ll) L. latrans; Lc) L. chaquensis; Dmu) Dermatonotus muelleri; Lms) L. mystacinus; En) Eupemphix nattereri; Lf) L. fuscus; Lmy) L. mystaceus; Lp) L. podicipinus; Pm) Physalaemus marmoratus; Lfn) L. furnarius; Pce) P. centralis; Pc) P. cuvieri; Ec) Elachistocleis cesarii; Ca) Chiasmocleis albopunctata; Eb) E. bicolor; Pmy) Pseudopaludicola mystacalis; Pf I) Pseudopaludicola sp. (aff. falcipes I); e Pf II) Pseudopaludicola sp. (aff. falcipes II).

Figure 3. Snout-vent length of anuran species recorded in the northwestern region of São Paulo. Rs) Rhinella schneideri; Hf) Hypsiboas faber; Tt) Trachycephalus typhonius; Hl) H. lundii; Ro) R. ornata; Hr) H. raniceps; Pp) Pseudis plantensis; Ha) H. albopunctatus; Sfv) Scinax fuscovarius; Pa) Phyllomedusa azurea; Ss) S. sp. (aff. similis); Dme) Dendropsophus melanargyreus; De) D. elianeae; Sfm) S. fuscomarginatus; Ds) D. sanborni; Sb) S. berthae; Dmi) D. minutus; Dn) D. nanus. Llb) Leptodactylus labyrinthicus; L1) L. latrans; Lc) L. chaquensis; Dmu) Dermatonotus muelleri; Lms) L. mystacinus; En) Eupemphix nattereri; Lf) L. fuscus; Lmy) L. mystaceus; Lp) L. podicipinus; Pm) Physalaemus marmoratus; Lfn) L. furnarius; Pce) P. centralis; Pc) P. cuvieri; Ec) Elachistocleis cesarii; Ca) Chiasmocleis albopunctata; Eb) E. bicolor; Pmy) Pseudopaludicola mystacalis; Pf I) Pseudopaludicola sp. (aff. falcipes I); and Pf II) Pseudopaludicola sp. (aff. falcipes II). 
Espécies

Família Bufonidae

Rhinella schneideri

Rhinella ornata

Família Hylidae

Dedropsophus elianeae Dedropsophus melanargyreus

Dedropsophus minutus

Dedropsophus nanus

Dedropsophus sanborni

Hypsiboas albopunctatus

Hypsiboas faber

Hypsiboas lundii

Hypsiboas raniceps

Phyllomedusa azurea

Pseudis platensis

Scinax berthae

Scinax fuscomarginatus

Scinax fuscovarius

Scinax sp. (aff. similis)

Trachycephalus typhonius

Família Leptodactylidae

Leptodactylus chaquensis

Leptodactylus furnarius

Leptodactylus fuscus

Leptodactylus labyrinthicus

Leptodactylus mystaceus

Leptodactylus mystacinus

Leptodactylus latrans

Leptodactylus podicipirus

Família Leiuperidae

Eupemphix nattereri

Physalaemus cuvieri

Physalaemus centralis

Physalaemus marmoratus

Pseudopaludicola sp. (aff. falcipes I)

Pseudopaludicola sp. (aff. falcipes II)

Pseudopaludicola mystacalis

Família Microhylidae

Chiasmocleis albopunctata

Dermatonotus muelleri

Elachistocleis bicolor

Elachistocleis cesarii
Meses

Jan. Fev. Mar. Abr. Maio Jun. Jul. Ago. Set. Out. Nov. Dez.

Referências
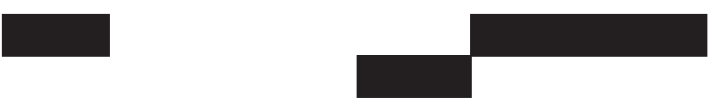

Rossa-Feres \& Nomura (2006)

Toledo et al. (2003)
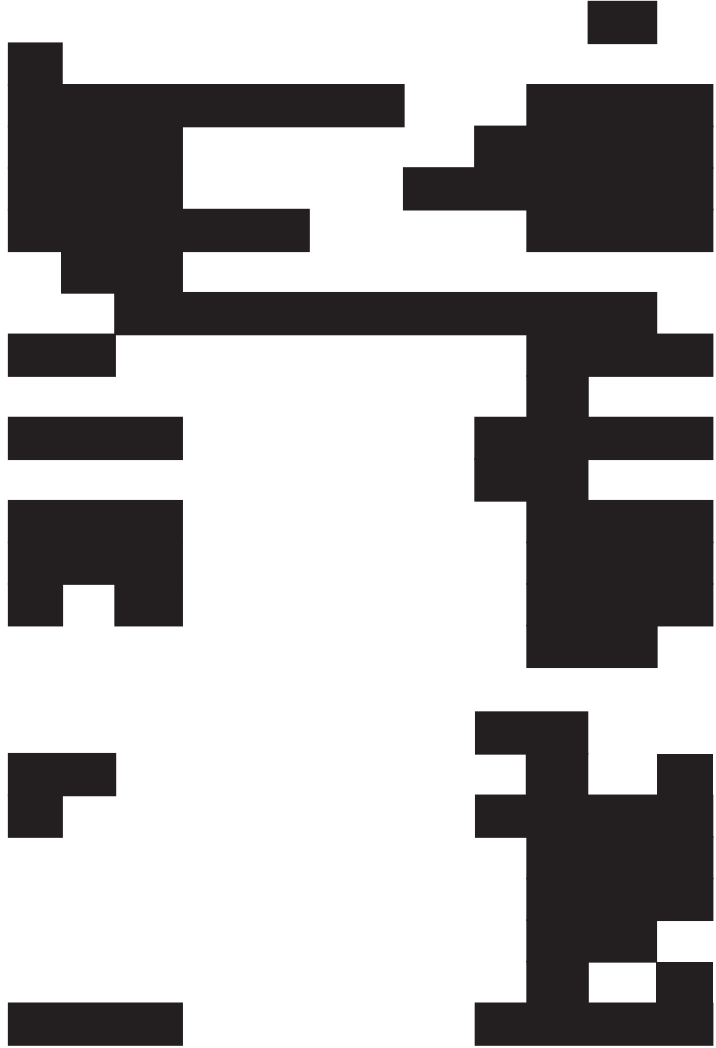

Vasconcelos \& Rossa-Feres (2005)

Silva \& Rossa-Feres (2007)

Rossa-Feres \& Nomura (2006)

Rossa-Feres \& Nomura (2006)

Prado (2009)

Silva \& Rossa-Feres (2007)

Rossa-Feres \& Nomura (2006)

Rossa-Feres \& Nomura (2006)
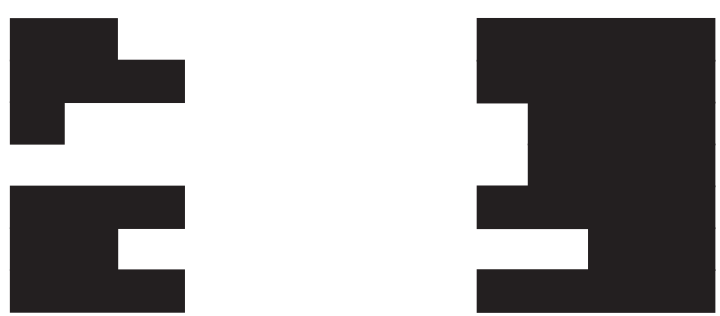

Rossa-Feres \& Nomura (2006)

Rossa-Feres \& Nomura (2006)

Rossa-Feres \& Nomura (2006)

Rossa-Feres \& Nomura (2006)

Santos et al. (2007)

Candeira (2007)

Silva (2007)

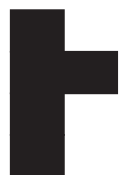

Silva et al. (2009)

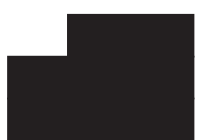

Rossa-Feres \& Nomura (2006)

Rossa-Feres \& Nomura (2006)

Rossa-Feres \& Nomura (2006)

Figura 4. Distribuição temporal das espécies de anuros registradas na região noroeste de São Paulo.

Figure 4. Temporal distribution of anuran species recorded in the northwestern region of São Paulo. 


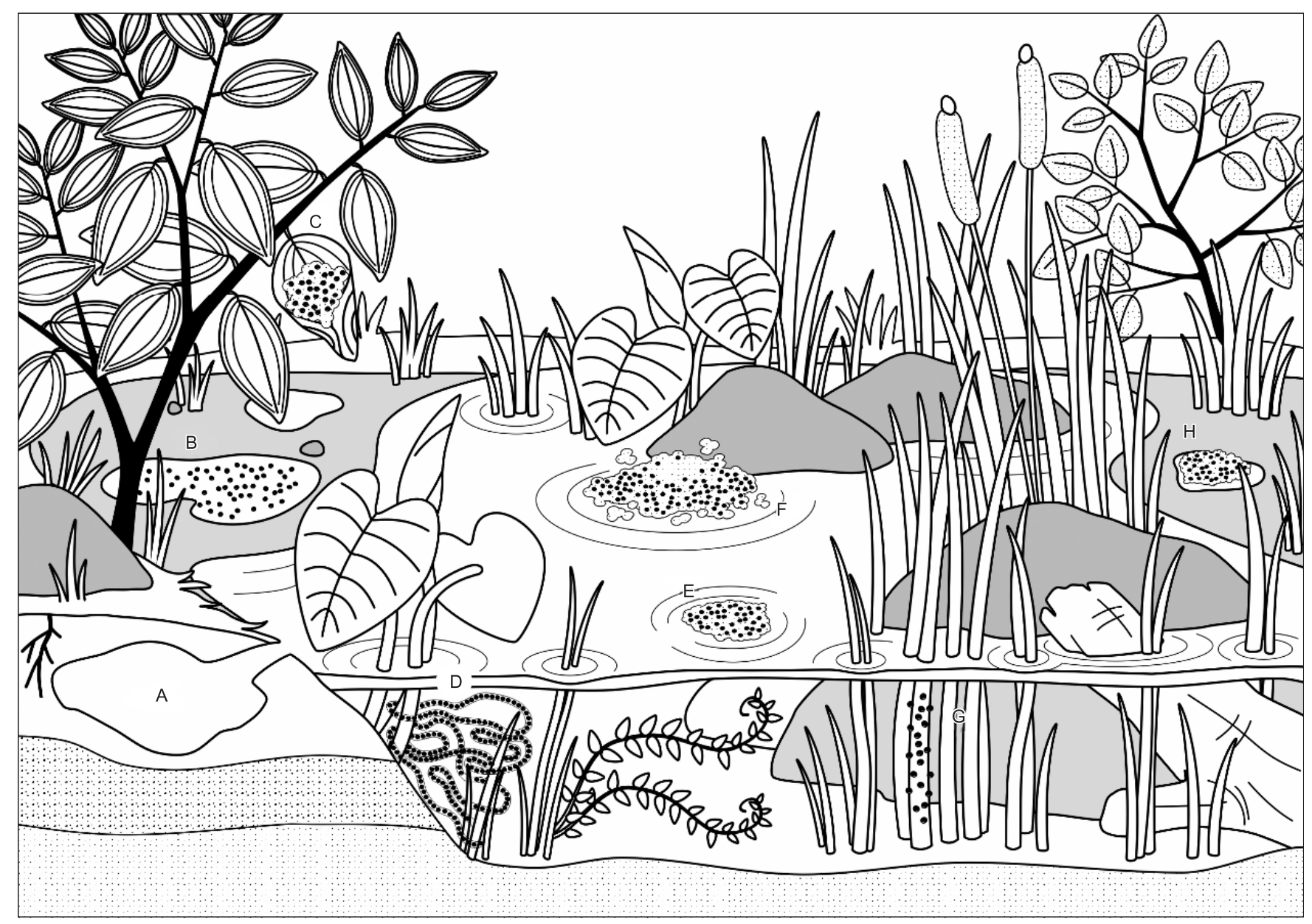

Figura 5. Modos reprodutivos (sensu Haddad \& Prado 2005) exibidos pelas espécies de anuros registrados na região noroeste de São Paulo. A) Modo 30, exibido por espécies do grupo fuscus do gênero Leptodactylus; B) Modo 4, exibido por espécies do grupo faber do gênero Hypsiboas; C) Modo 24, exibido por Phyllomedusa azurea; D) Modo 1 com desova em cordão gelatinoso, exibido por espécies do gênero Rhinella; E) Modo 1 com desova em massa gelatinosa flutuante, exibido por espécies dos gêneros Hypsiboas, Trachycephalus, Chiasmocleis, Dermatonotus e Elachistocleis; F) Modo 11, exibido pelas espécies da família Leiuperidae e espécies do grupo latrans do gênero Leptodactylus; G) Modo 1 com desova em massa gelatinosa aderida à vegetação submersa, exibido por espécies dos gêneros Dendropsophus, Pseudis e Scinax; H) Modo 13 desova em ninho de espuma depositada em cavidade construída na margem de poças, exibido por Leptodactylus labyrinthicus L. mystaceus e L. podicipinus.

Figure 5. Reproductive modes (sensu Haddad \& Prado 2005) presented by the anuran species recorded in the northwestern region of São Paulo state. A) Mode 30, presented by species of the fuscus group of the genus Leptodactylus; B) Mode 4, presented by species of the faber group of the genus Hypsiboas; C) Mode 24, presented by Phyllomedusa azurea; D) Mode 1 with gelatinous egg strings, presented by species of the genus Rhinella; E) Mode 1 with egg clutches in a floating gelatinous mass, presented by species of the genera Hypsiboas, Trachycephalus, Chiasmocleis, Dermatonotus and Elachistocleis; F) Mode 11, presented by species of the family Leiuperidae and species of the latrans group of the genus Leptodactylus; G) Mode 1 with egg clutches in gelatinous mass attached to submerged vegetation, presented by species of the genera Dendropsophus, Pseudis and Scinax; H) Mode 13 foam nest floating on water accumulated in construct basis in ponds, presented by Leptodactylus labyrinthicus, L. mystaceus and L. podicipinus. 

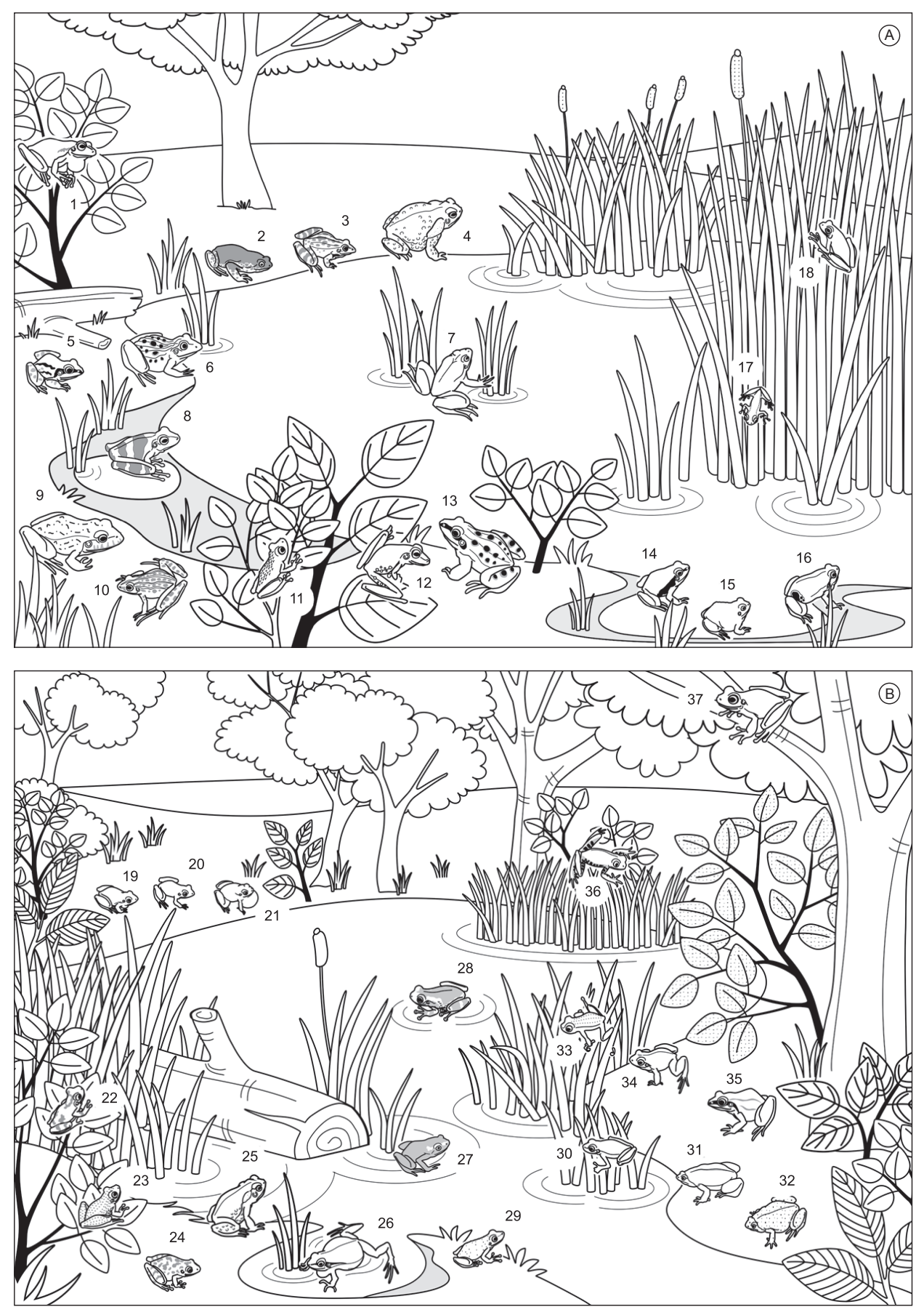

Figura 6. Sítio de vocalização e uso de habitat das espécies de anuros registradas na região noroeste de São Paulo. A) 1) Hypsiboas raniceps; 2) Dermatonotus muelleri; 3) Leptodactylus fuscus; 4) Rhinella schneideri; 5) Leptodactylus mystacinus; 6) Leptodactylus chaquensis; 7) Pseudis platensis; 8) Hypsiboas faber; 9) Leptodactylus labyrinthicus; 10) Leptodactylus furnarius; 11) Scinax berthae; 12) Hypsiboas albopunctatus; 13) Leptodactylus latrans; 14) Physalaemus centralis; 15) Physalaemus marmoratus; 16) Eupemphix nattereri; 17) Dendropsophus sanborni; 18) Dendropsophus minutus. B) 19) Pseudopaludicola sp. (aff. falcipes I); 20) Pseudopaludicola sp. (aff. falcipes II); 21) Pseudopaludicola mystacalis; 22) Dendropsophus melanargyreus; 23) Scinax fuscomarginatus; 24) Scinax fuscovarius; 25) Rhinella ornata; 26) Physalaemus cuvieri; 27) Trachycephalus typhonius; 28) Chiasmocleis albopunctata; 29) Scinax sp. (aff. similis); 30) Dendropsophus elianeae; 31) Elachistocleis bicolor; 32) Elachistocleis cesarii; 33) Dendropsophus nanus; 34) Leptodactylus podicipinus; 35) Leptodactylus mystaceus; 36) Phyllomedusa azurea; e 37) Hypsiboas lundii.

Figure 6. Calling site and habitat use of anuran species recorded in the northwestern region of São Paulo state. A) 1) Hypsiboas raniceps; 2) Dermatonotus muelleri; 3) Leptodactylus fuscus; 4) Rhinella schneideri; 5) Leptodactylus mystacinus; 6) Leptodactylus chaquensis; 7) Pseudis platensis; 8) Hypsiboas faber; 9) Leptodactylus labyrinthicus; 10) Leptodactylus furnarius; 11) Scinax berthae; 12) Hypsiboas albopunctatus; 13) Leptodactylus latrans; 14) Physalaemus centralis; 15) Physalaemus marmoratus; 16) Eupemphix nattereri; 17) Dendropsophus sanborni; 18) Dendropsophus minutus. B) 19) Pseudopaludicola sp. (aff. falcipes I); 20) Pseudopaludicola sp. (aff. falcipes II); 21) Pseudopaludicola mystacalis; 22) Dendropsophus melanargyreus; 23) Scinax fuscomarginatus; 24) Scinax fuscovarius; 25) Rhinella ornata; 26) Physalaemus cuvieri; 27) Trachycephalus typhonius; 28) Chiasmocleis albopunctata; 29) Scinax sp. (aff. similis); 30) Dendropsophus elianeae; 31) Elachistocleis bicolor; 32) Elachistocleis cesarii; 33) Dendropsophus nanus; 34) Leptodactylus podicipinus; 35) Leptodactylus mystaceus; 36) Phyllomedusa azurea; and 37) Hypsiboas lundii. 

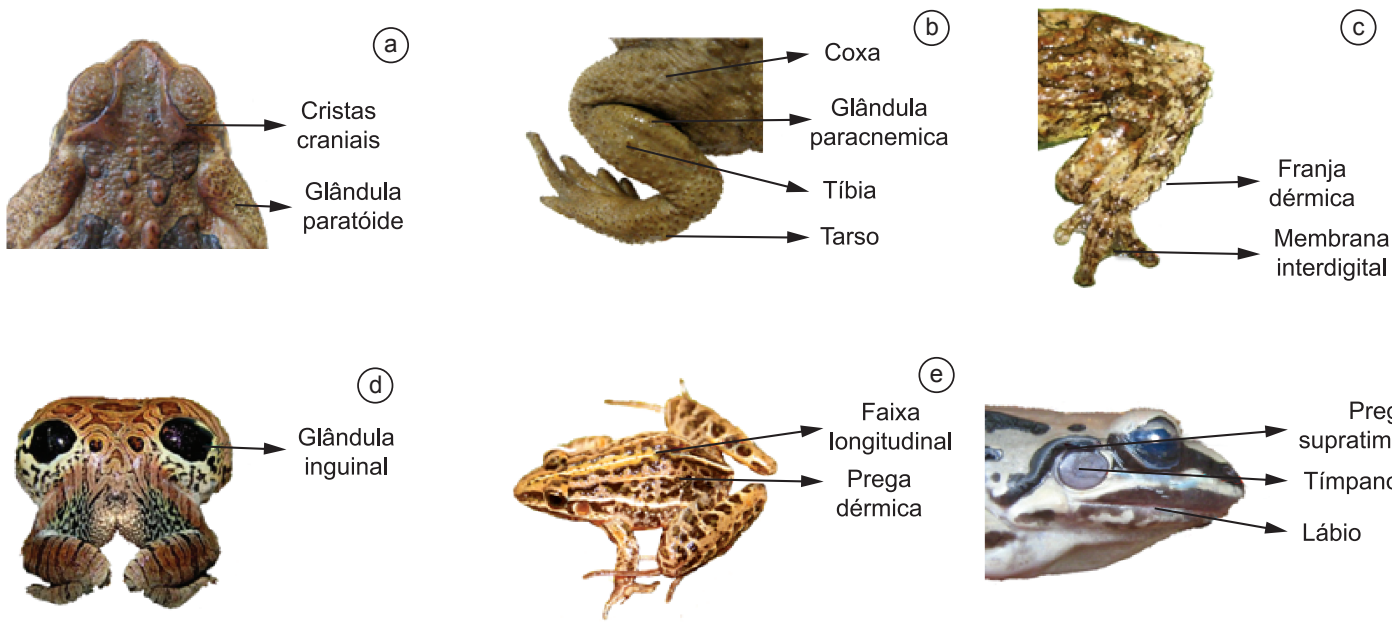

(e)
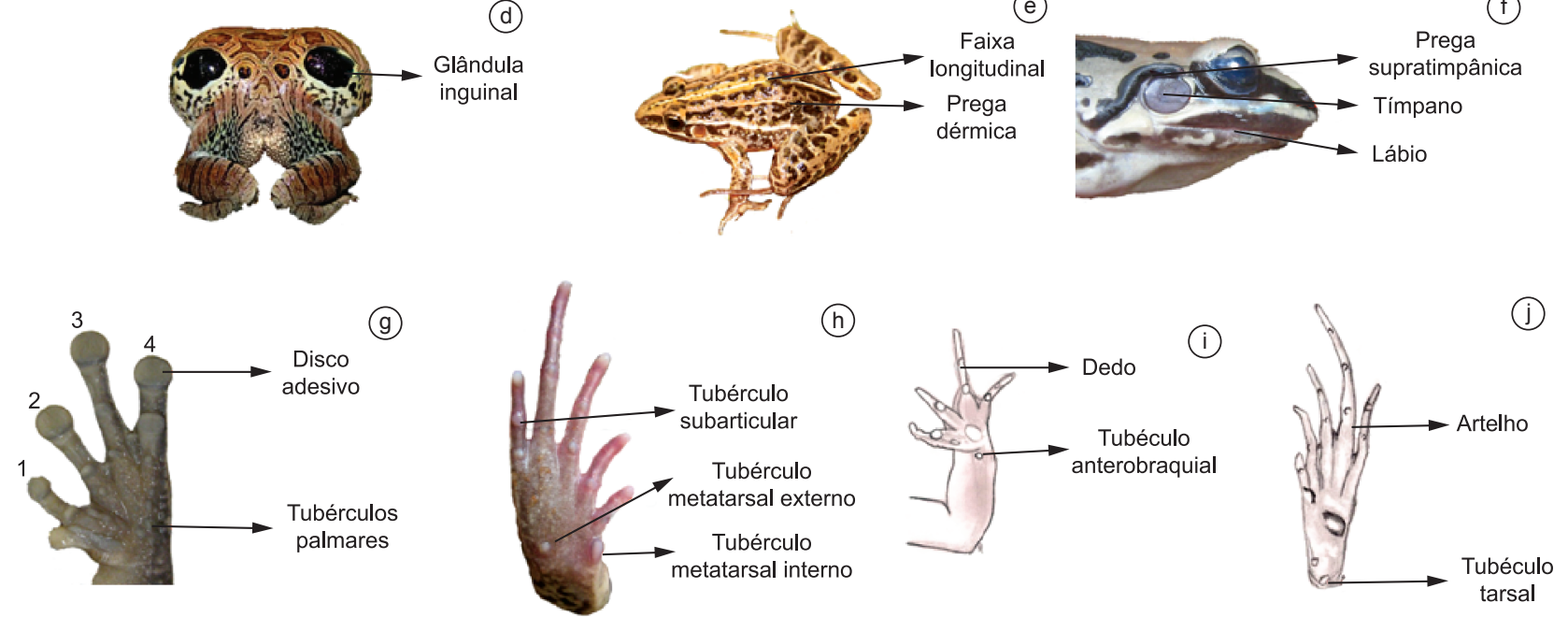

Figura 7. Algumas características morfológicas utilizadas na chave de identificação. a) região cefálica de Rhinella schneideri; b) membro posterior de Rhinella schneideri; c) membro posterior de Dendropsophus melanargyreus; d) região inguinal de Eupemphix nattereri; e) Leptodactylus furnarius; f) região cefálica de Leptodactylus mystacinus; g) membro anterior de Hypsiboas faber; h) membro posterior de Leptodactylus mystacinus; i) membro anterior de Pseudopaludicola; e j) membro posterior de Physalaemus.

Figure 7. Some morphological characteristics used in the taxonomic key. a) Cephalic region of Rhinella schneideri; b) hindlimb of Rhinella schneideri; c) hindlimb of Dendropsophus melanargyreus; d) inguinal region of Eupemphix nattereri; e) Leptodactylus furnarius; f) cephalic region of Leptodactylus mystacinus; g) forelimb of Hypsiboas faber; h) hindlimb of Leptodactylus mystacinus; i) forelimb of Pseudopaludicola; and j) hindlimb of Physalaemus.

\section{Agradecimentos}

Gostaríamos de agradecer a todos os alunos do laboratório de Ecologia Animal, da UNESP campus São José do Rio Preto e da disciplina do Programa de Pós-graduação em Biologia Animal "Origem, Diversidade e Biologia de Lissamphibia", que testaram esta chave de identificação previamente à sua publicação: Cibele G. Cassoli, Estela R. Pinto, Fabiane F. Martins, Gustavo C. O. Piccoli, Heloisa J. Almeida, Leonardo S. Gedraite, Lucas B. Crivellari, Mainara J. Xavier, Pablo A. P. Antiqueira, Thiago A. L. de Oliveira, Thiago G. Souza e Veronica T. T. de Souza. Itamar A. Martins, Lia R. S. Borges, Mario A. Sacramento, Renato Gaiga, Gustavo Canella e Vitor H. M. do Prado disponibilizaram fotos de algumas espécies. Ulisses Caramaschi confirmou a identificação de Elachistocleis cesarii. Este trabalho foi financiado pela Fundação de Amparo à Pesquisa do Estado de São Paulo por meio de bolsas de mestrado e doutorado concedidas a DBP, FRS e MVG (processos: 08/55744-6, 07/50738-5, 08/50575-1). O levantamento de fauna que permitiu a reunião de todos os dados apresentados neste estudo foi feito no âmbito dos projetos BIOTA/FAPESP (processos: 01/13341-3, 04/04820-3). DCRF é bolsista do CNPq.

\section{Referências Bibliográficas}

AB'SABER, A.N. 2003. Os domínios de natureza no Brasil: potencialidades paisagísticas. Ateliê Editorial, São Paulo.
ALVES, A.C.R. \& CARVALHO-E-SILVA, S.P. 1999. Descrição da larva de Scinax similis (Cochran) com notas comparativas sobre o grupo "ruber" no sudeste do Brasil (Amphibia, Anura, Hylidae). Rev. Bras. Zool. 16(2):507-512. http://dx.doi.org/10.1590/S0101-81751999000200016

ARAÚJO, O.G.S., TOLEDO, L.F., GARCIA, P.C.A. \& HADDAD, C.F.B. 2009. The amphibians of São Paulo State. Biota Neotrop. 9(4): http://www. biotaneotropica.org.br/v9n4/en/abstract?inventory+bn03109042009. (último acesso em 22/12/2010). http://dx.doi.org/110.1590/S167606032009000400020

BARCHA, S.F. \& ARID, F.M. 1971. Estudo da evapotranspiração na região norte-ocidental do Estado de São Paulo. R. Cient. Fac. Ci. Lctr. Votuporanga 1:97-122.

BERNARDE, P.S. \& KOKUBUM, M.N.C. 1999. Anurofauna do Município de Guararapes, Estado de São Paulo, Brasil (AMPHIBIA, ANURA). Acta Biol. Leop. 21:89-97.

CAIS, A. 1992. Aspectos biológicos e status taxonômico de Hyla biobeba Bokermann \& Sazima, 1973 (Amphibia, Anura). Tese de doutorado, Universidade Estadual Paulista, Rio Claro.

DE SÁ, R.O., Dubois, A. \& Ohler, A. 2007. Designation of a neotype for Leptodactylus gracilis (Duméril and Bibron, 1840) (Amphibia: Leptodactylidae). S. Am. J. Herpetol. 2:175-178.

DUARTE, T.C., VEIGA-MENONCELLO, A.P.C., LIMA, J.R.F., STRUSSMANN, C., DEL-GRANDE M.L., GIARETTA, A.A., PEREIRA, E.G., ROSSA-FERES, D.C. \& RECCO-PIMENTEL, S.M. 2010. Chromosome analysis in Pseudopaludicola (Anura: Leiuperidae), with description of sex chromosomes $\mathrm{XX} / \mathrm{XY}$ in $P$. saltica. Hereditas 147:43-52. PMid:20536541. http://dx.doi.org/10.1111/j.16015223.2009.02153.x 
DUELLMAN, W.E. 1999. Distribution patterns of amphibians in the South America. In Patterns of distribution of amphibians - a global perspective. (W.E. Duellman, ed.). Johns Hopkins University Press, Baltimore, p. 255-327.

DUELLMAN, W.E. \& TRUEB, 1. 1986. Biology of amphibians. McGrawHill, New York.

FÁVERO, E.R., VEIGA-MENONCELLO, A.C.P., ROSSA-FERES, D.C., STRUSSMANN, C., GIARETTA. A.A., ANDRADE, G.V. \& RECCO-PIMENTEL, S.M. 2011. Intrageneric karyotypic variation in Pseudopaludicola (Anura, Leiuperidae). Zoological Studies, in press.

FROST, D.R. 2010. Amphibian Species of the World: an Online Reference. Version 5.4. http://research.amnh.org/herpetology/amphibia (último acesso em 15/07/2010).

HADDAD, C.F.B. \& PRADO, C.P.A. 2005. Reproductive modes in frogs and their unexpected diversity in the Atlantic Forest of Brazil. Bioscience 55(3):207-217. http://dx.doi.org/10.1641/0006-3568(2005)055[0207:RM IFAT]2.0.CO;2

KRONKA, F.J.N., MATSUKUMA, C.K., NALON, M.A., DELCALI, I.H., ROSSI, M., MATTOS, I.F.A., SHIN-IKE, M.S. \& PONTINHAS, A.A.S 1993. Inventário florestal do Estado de São Paulo. Instituto Florestal, São Paulo.

LAVILLA, E.O., LANGONE, J.A., CARAMASCHI, U., HEYER, W.R. \& DE SÁ, R.O. 2010. The identification of Rana ocellata Linnaeus, 1758. Nomenclatural impact on the species currently known as Leptodactylus ocellatus (Leptodactylidae) and Osteopilus brunneus (Gosse, 1851) (Hylidae). Zootaxa 2346:1-16.

NOMURA, F. 2003. Ecologia reprodutiva e comportamento de forrageio e escavação de Dermatonotus muelleri (Boettger, 1885) (Anura, Microhylidae). Dissertação de mestrado, Universidade Estadual Paulista, São José do Rio Preto.

PRADO, V.H.M. 2009. Uso de remanescentes florestais pela anurofauna da região noroeste do estado de São Paulo. Tese de doutorado, Universidade Estadual Paulista, São José do Rio Preto.

PRADO, V.H.M., BORGES, R., SILVA, F.R., TOGNOLO, T.T. \& ROSSAFERES, D.C. 2008. Amphibia, Anura, Hylidae, Phyllomedusa azurea: Distribution extension. Check List 4(1):55-56.

RODRIGUES, R.R., JOLY, C.A., BRITO, M.C.W., PAESE, A., METZGER, J.P., CASSATI, L., NALON, M.A., MENEZES, N., IVANAUSKAS, N.M., BOLZANI, V. \& BONONI, V.L.R. 2008. Diretrizes para conservação e restauração da biodiversidade no Estado de São Paulo. Governo do Estado de São Paulo, São Paulo.

ROSSA-FERES, D.C. \& JIM, J. 2001. Similaridade no sítio de vocalização em uma comunidade de anfíbios anuros na região noroeste do Estado de São Paulo, Brasil. Rev. Bras. Zool. 18 (2):439-454. http://dx.doi. org/10.1590/S0101-81752001000200015

ROSSA-FERES, D.C. \& NOMURA, F. 2006. Morphological characterization and taxonomic key for tadpoles (Amphibia: Anura) from northwestern region of São Paulo state, Brazil. Biota Neotropica 6 (1): http://www.biotaneotropica.org.br/v6n1/pt/abstract?identificationkey+bn00706012006 (último acesso em 22/12/2010). http://dx.doi. org/10.1590/S1676-06032006000100014

ROSSA-FERES, D.C., MARTINS, M., MARQUES, O.A.V., MARTINS, I.A., SAWAYA, R.J. \& HADDAD, C.F.B. 2008. Herpetofauna. In Diretrizes para a conservação e restauração da biodiversidade no estado De São Paulo (R.R. RODRIGUES, C.A. JOLY, M.C.W. DE BRITO, A PAESE, J.P. METZGER, L. CASATTI, M.A. NALON, N. MENEZES, N.M. IVANAUSKAS, V. BOLZANI, V.L.R. BONONI, Coords.). Instituto de Botânica; Fapesp, São Paulo, p.83-94.

ROSSA-FERES, D.C., SAWAYA, R.J., FAIVOVICH, J., GIOVANELLI, J.G.R., BRASILEIRO, C.A., SCHIESARI, L., ALEXANDRINO, J. \& HADDAD, C.F.B. 2011. Anfíbios do Estado de São Paulo, Brasil: conhecimento atual e perspectivas. Biota Neotropica 11 (1a): http://www. biotaneotropica.org.br/v11n1a/pt/abstract?inventory+bn0041101a2011
RUDORFF, B.F.T., BERKA, L.M.S., XAVIER, A.C., MOREIRA, M.A., DUARTE, V., ROSA, V.G.C. \& SHIMABUKURO, W.E. 2004. Estimativa de área plantada com cana-de-açúcar em municípios do estado de São Paulo por meio de imagens de satélites e técnicas de geoprocessamento: ano safra 2003/2004. Ministério da Ciência e Tecnologia - Instituto Nacional de Pesquisas Espaciais, São José dos Campos.

SANTOS, T.G. \& ROSSA-FERES, D.C. 2007. Similarities in calling site and advertisement call among anuran amphibians in southeastern Brazil. S. Am. J. Herpetol. 2(1):17-30 http://dx.doi.org/10.2994/18089798(2007)2[17:SICSAA]2.0.CO;2

SANTOS, T.G., ROSSA-FERES, D.C. \& CASATTI, L. 2007. Diversidade e distribuição espaço-temporal de anuros em região com pronunciada estação seca no sudeste do Brasil. Iheringia 97(1):37-49. http://dx.doi. org/10.1590/S0073-47212007000100007

SANTOS, T.G., VASCONCELOS, T.S., ROSSA-FERES, D.C. \& HADDAD, C.F.B. 2009. Anurans of a seasonally dry tropical forest: Morro do Diabo State Park, São Paulo state, Brazil. J. Nat. Hist. 43(15):973-993.

SILVA, F.R., PRADO, V.H.M. \& ROSSA-FERES, D.C. 2010. Amphibia, Anura, Hylidae, Dendropsophus melanargyreus: Distribution extension, new state record and geographic distribution map. Check List 6(3):402404.

SILVA, F.R., PRADO, V.H.M., VASCONCELOS, T.S., SANTOS, T.G. \& ROSSA-FERES, D.C. 2009. Amphibia, Anura, Microhylidae, Chiasmocleis albopunctata: Filling gap and geographic distribution map. Check List 5(2):314-316.

SILVA, F.R. \& ROSSA-FERES, D.C. 2007. Uso de fragmentos por anuros (Amphibia) de área aberta na região noroeste do Estado de São Paulo. Biota Neotrop. 7(2): http://www.biotaneotropica.org.br/v7n2/pt/ abstract?article+bn03707022007 (último acesso em 22/12/2010). http:// dx.doi.org/10.1590/S1676-06032007000200016

SILVA, R.A., MARTINS, I.A. \& ROSSA-FERES, D.C. 2008. Bioacústica e sítio de vocalização em taxocenoses de anuros de área aberta no noroeste paulista. Biota Neotrop. 8(3): http://www.biotaneotropica.org.br/v8n3/en/ abstract?article+bn01608032008 (último acesso em 22/12/2010). http:// dx.doi.org/10.1590/S1676-06032008000300012

SILVEIRA, T. 2002. Região desmata 15 mil hectares em dez anos. Jornal da Cidade, Bauru - SP. http://www.biodiversityreporting.org/index.php?pa geId $=$ sub \&c $=$ Brazil \&cRef $=$ Brazil\&lang=en_US\&year $=2003 \&$ currentIt em=mainMenu_1 (último acesso em 09/03/2007).

SOCIEDADE BRASILEIRA DE HERPETOLOGIA - SBH. 2010. Brazilian amphibians - List of species. http://www.sbherpetologia.org.br (último acesso em 15/07/2010).

SPECIESLINK. NetworkManager. http://splink.cria.org.br/manager/ details?resource $=$ DZSJRP-Amphibia-adults\&setlang=pt (ultimo acesso em: 22/12/2010)

VASCONCELOS, T.S. \& ROSSA-FERES, D.C. 2005. Diversidade, distribuição espacial e temporal de anfíbios anuros (Amphibia, Anura) na região noroeste do Estado de São Paulo, Brasil. Biota Neotrop. 5(2): http:// www.biotaneotropica.org.br/v5n2/pt/abstract?article+BN01705022005 (último acesso em 22/12/2010). http://dx.doi.org/10.1590/S167606032005000300010

VASCONCELOS, T.S. \& ROSSA-FERES, D.C. 2008. Habitat heterogeneity and use of physical and acoustic space in anuran communities in Southeastern Brazil. Phyllomedusa 7(2):127-142.

VASCONCELOS, T.S., SANTOS, T.G., HADDAD, C.F.B. \& ROSSAFERES, D.C. 2010. Climatic variables and altitude as predictors of anurans species richness and number of reproductive modes in Brazil. J. Trop. Ecol. 26:423-432. http://dx.doi.org/10.1017/S0266467410000167

VIZOTTO, L.D. 1967. Desenvolvimento de anuros da região norte-ocidental do Estado de São Paulo. Tese de doutorado, Universidade de São Paulo, São Paulo. 
Provete, D.B. et al.

Chave dicotômica de identificação para anfíbios anuros do noroeste paulista

1a. Cristas craniais presentes (Figura 7a); pele áspera; membranas interdigitais entre os dedos ausentes e bastante reduzidas ou ausentes entre os artelhos; glândulas parotóides presentes (Figura 7a) BUFONIDAE: Rhinella 2

1b. Cristas craniais ausentes; pele lisa ou pouco granulosa, sem protuberâncias; glândulas parotóides ausentes 3

2a. (1a) Glândula parotóide grande (Figura 7a), com comprimento superior a 25\% do CRC; glândula paracnêmica presente na região da tíbia (Figura 7b); CRC variando entre 120 e $160 \mathrm{~mm}$. Maioria dos indivíduos sem faixa creme na maxila superior ...... R. schneideri

2b. Glândula paratóide pequena, com comprimento inferior a 20\% do CRC; glândula paracnêmica ausente; CRC variando entre 52 e 70 mm; a maioria dos indivíduos com uma faixa creme na maxila superior, que se estende do lábio superior até a margem do olho; presença de uma faixa branca vertebral no dorso

R. ornata

3a. (1b) Corpo ovoide ou globular, com exceção de Chiasmocleis, que apresenta corpo esguio e alongado; focinho acuminado; cabeça pequena e triangular; com um único tubérculo metatarsal pouco desenvolvido (Figura 7h); tímpano indistinguível; artelho III maior que artelho V (Figura G); ventre sem grânulos; membros reduzidos, com dedos pequenos sem discos adesivos e com tubérculos subarticulares

MICROHYLIDAE 4

3b. Corpo alongado na maioria das espécies; com dois ou mais tubérculos metatarsais (ou um único tubérculo metatarsal bem desenvolvido em Pseudis platensis); tímpano distinguível (Figura F) (indistinguível em Pseudopaludicola); membro posterior bem desenvolvido 7

4a. (3a) Porte pequeno a médio (CRC entre 20 e $40 \mathrm{~mm}$ ); focinho estreito e acuminado

4b. Porte médio (CRC entre 43 e $67 \mathrm{~mm}$ ); ventre com manchas brancas esparsas; dorso com coloração olivácea; cabeça pequena, com clara divisão entre esta e o corpo; sem prega dérmica

Dermatonotus muelleri

5a. (4a) Focinho pontiagudo e triangular; presença de uma prega dérmica pós-timpânica separando claramente a cabeça do restante do corpo; corpo ovóide; ventre amarelo ou manchado em vida Elachistocleis 6

5b. Focinho arredondado; ausência de prega dérmica; corpo esguio com tronco alongado; presença de faixa esbranquiçada que se estende da região do focinho, canto rostralis e até as pálpebras superiores; coloração marrom quando fixado; às vezes com uma faixa branca transversal no dorso; ventre com pequenas manchas claras distribuídas irregularmente

Chiasmocleis albopunctata

6a (5a) Ventre uniformemente amarelo em vida, esbranquiçado quando fixado; CRC entre 19 e $31 \mathrm{~mm}$. E. bicolor

6b. Ventre irregularmente manchado de amarelo ou alaranjado, esbranquiçado com manchas quando fixado; CRC entre 22 e 35 mm

Elachistocleis sp.

7a (3b) Ausência de discos adesivos; dorso com pregas dérmicas distribuídas longitudinalmente (Figura 7e) ou com granulações irregulares; dedos bastante alongados, principalmente dedo IV; ausência de membranas interdigitais 8

7b. Presença de discos adesivos (Figura 7g) (ausentes somente em Pseudis platensis); dorso liso; dedos achatados dorso-ventralmente; presença de membranas interdigitais (Figura 7c) (em Pseudis platensis, membranas interdigitais entre os artelhos extremamente desenvolvidas)

HYLIDAE 22

8a. (7a) Glândula inguinal presente (Figura 7d) LEIUPERIDAE (em parte) 18

8b. Glândula inguinal ausente

9a. (8b) Porte médio a grande (CRC mínimo de $32 \mathrm{~mm}$, podendo ultrapassar $150 \mathrm{~mm}$ ); ausência de tubérculo tarsal; artelhos finos e longos; corpo com aspecto rombóide; artelhos sem membranas interdigitais LEPTODACTYLIDAE Leptodactylus 10

9b. Porte pequeno a médio (CRC variando de 10 a $55 \mathrm{~mm}$ ); presença de tubérculos anterobraquiais (Figura 7i) ou de tubérculos tarsais (Figura 7j); dorso com pequenos grânulos esparsos (às vezes em forma de $\Omega$ ); dentes vomerianos bastante reduzidos ou ausentes

LEIUPERIDAE 17 (emparte)

10a. (9a) Porte médio a grande (CRC variando de 32 a mais de $150 \mathrm{~mm}$ ); alguns indivíduos apresentam o dorso com diversas manchas em formato de ocelo (Figura 7e); ausência de mancha interocular em formato triangular 
Chave para anuros do noroeste paulista

10b. Porte médio (CRC variando entre 32 a $45 \mathrm{~mm}$ ); focinho arredondado em vista lateral; prega supratimpânica (Figura 7f) alcançando a axila; presença de uma mancha interocular em formato de triângulo invertido, com contorno bem definido; coloração dorsal marrom escuro em vida e depois de fixado; ventre com pequenas manchas brancas esparsas; presença de uma fileira de granulações no lábio inferior ..

L. podicipinus

11a. (10a) Presença de manchas em formato de ocelo distribuídas na região dorsal (Figura 7e); presença de seis ou mais pregas dérmicas longitudinais; sem fileiras de granulações na região dorsolateral 12

11b. Ausência de manchas em formato de ocelo na região dorsal; com até quatro pregas dérmicas longitudinais (Figura 7e); com fileiras de granulações na região dorsolateral

12a. (11a) Porte médio (CRC variando entre 33 a $50 \mathrm{~mm}$ ); presença de seis pregas dérmicas longitudinais na região dorsal e dorsolateral ..

12b. Porte médio a grande, com CRC variando entre 70 a $120 \mathrm{~mm}$; presença de oito ou mais pregas dérmicas longitudinais 14

13a. (12a) Pernas longas (comprimento da perna/CRC entre 57 e 72\%); CRC variando entre 31 e 45 mm; estreita faixa longitudinal (Figura 7e), de coloração creme sempre presente ao longo da coluna vertebral; corpo delgado; focinho extremamente pontudo ...... L. furnarius

13b. Pernas curtas (comprimento da perna/CRC entre 42 e 60\%); CRC variando entre 40 e 50 mm; às vezes apresenta faixa larga de coloração creme na região dorsal, ao longo da coluna vertebral; corpo robusto; focinho pontudo L. fuscus

14a. (12b) Antebraço dos machos hipertrofiado; face posterior da coxa reticulada em exemplares preservados; comprimento da perna cerca de $20 \%$ maior que o CRC; saco vocal único; ventre com manchas irregulares

L. latrans

14b. Antebraço dos machos nunca é hipertrofiado; face posterior da coxa com mancha verde oliva uniforme, em exemplares preservados esta torna-se inconspícua; comprimento da perna cerca de $10 \%$ maior que o CRC; saco vocal duplo; ventre com poucas e pequenas manchas irregulares e esparsas

L. chaquensis

15a. (11b) Porte pequeno a médio (CRC inferior a $70 \mathrm{~mm}$ ); presença de uma única faixa escura da ponta do focinho ao olho (Figura $7 \mathrm{f})$....

15b. Porte grande (CRC superior a $100 \mathrm{~mm}$ ); lábio (Figura 7f) superior com faixas verticais estreitas escuras intercaladas com faixas claras; machos adultos em período reprodutivo com espinhos peitorais e espinho na base do dedo II; ventre escuro com manchas brancas de formato irregular, formando um "labirinto"; em vida, parte posterior da coxa escura com manchas avermelhadas vermiculadas, em indivíduos preservados o vermelho muda para branco L. labyrinthicus

16a. (15a) Focinho pontiagudo em vista lateral; diâmetro do olho maior que a distância olho-narina; diâmetro do olho 1,5 vezes maior que o diâmetro do tímpano; ausência de faixa longitudinal preta na região dorsolateral do corpo L. mystaceus

16b. Focinho arredondado em vista lateral; diâmetro do olho igual à distância olho-narina; três pares de fileiras de granulações longitudinais na região dorsolateral do corpo; presença de uma faixa preta longitudinal e de manchas irregulares, também de coloração preta, na região dorsolateral L. mystacinus

17a (9b) Tímpano distinto; tubérculo metatarsal pequeno (Figura 7h) variando entre 1,13 a 1,32 mm de comprimento; CRC variando entre 25 a $45 \mathrm{~mm}$ grupo de Physalaemus cuvieri 19

17b. Tímpano indistinto; tubérculo tarsal ausente; presença de um tubérculo anterobraquial (Figura 7i); CRC variando entre 10 e 22 mm; tubérculo palmar arredondado (Figura 7g); na maioria das espécies há uma prega que se estende desde a margem lateral do tubérculo subarticular (Figura 7h) basal do artelho V, até a ponta do tubérculo metatarsal externo (Figura 7h) Pseudopaludicola 20

18a. (8a) Glândulas inguinais ovais, com ocelos escuros (Figura 7d); membrana timpânica não evidente; tubérculo tarsal ausente; presença de faixas transversais irregulares de coloração castanho escura na região dorsal; coloração dorsal creme ou avermelhada em vida; ausência de glândulas dorsais Eupemphix nattereri

18b. Glândula inguinal reniforme sem ocelos escuros; tubérculo tarsal presente (Figura 7j); presença de faixas irregulares de coloração castanhoclaro na região dorsal; coloração dorsal avermelhada em vida; presença de glândulas dorsais Physalaemus marmoratus 
Provete, D.B. et al.

19a. (17a) Largura e comprimento da cabeça com aproximadamente o mesmo tamanho; comprimento da cabeça com aproximadamente $1 / 3$ do comprimento do corpo; glândulas sacrais pequenas ou não evidentes; coloração dorsal marrom escuro, podendo variar para verde, mas nunca vermelho; saco vocal claro; parte interna da coxa avermelhada ou alaranjada em vida; CRC variando entre 25 e 35 mm ......

Physalaemus cuvieri

19b. Largura da cabeça com 1/3 a 1/4 do comprimento do corpo; glândulas sacrais evidentes; presença de dois pequenos ocelos na região sacral; coloração dorsal cinza escuro, podendo variar para vermelho, mas nunca verde; CRC variando entre 33 e $40 \mathrm{~mm}$

Physalaemus centralis

20a. (17b) Presença de asperezas nupciais na base do dedo II em machos adultos; ausência de discos arredondados nos dedos (Figura 7g); pele lisa, às vezes com pequenos grânulos esparsos 21

20b. Corpo robusto; focinho pontiagudo; falange terminal pontiaguda e estreita; pele do dorso grossamente granulada; ventre esbranquiçado, sem manchas Pseudopaludicola sp. (aff. mystacalis)

21a. (20a) Corpo ovalado, presença de uma mancha de coloração vermelho ferrugem atrás dos olhos e nos flancos; coloração dorsal castanho acinzentado em vida; região ventral clara sem manchas; focinho oval em vista dorsal.

Pseudopaludicola sp. (aff. falcipes)

21b. Corpo alongado e esguio; às vezes com uma listra longitudinal da ponta do focinho até a cloaca; coloração dorsal castanho escuro uniforme, sem manchas; região ventral uniformemente clara; focinho pontudo em vista dorsal Pseudopaludicola sp. (aff. canga)

22a (7b) Pupila horizontal; membranas interdigitais pouco desenvolvidas ou ausentes nos membros anteriores, mas bem desenvolvidas no membro posterior na maioria das espécies; disco adesivo desenvolvido (ausentes em Pseudis platensis)

HYLINAE 23

22b. Pupila vertical; membranas interdigitais ausentes nos membros anteriores e extremamente reduzidas nos membros posteriores; disco adesivo pouco desenvolvido; presença de numerosos tubérculos palmares (Figura $7 \mathrm{~g}$ ); polegares preênseis; coloração dorsal verde em vida, em animais fixados azul ou violeta; presença de faixas verticais escuras nas coxas, com coloração amarelo-alaranjada em vida e esbranquiçada em animais fixados

PHYLLOMEDUSINAE: Phyllomedusa azurea

23a. (22a) Membros posteriores alongados e delgados; membranas interdigitais desenvolvidas nos artelhos (Figura 7c) e pouco desenvolvidas ou ausentes nos dedos; discos adesivos presentes

23b. Membros posteriores hipertrofiados; membranas interdigitais bastante desenvolvidas nos artelhos, mas reduzidas entre os dedos 3 e 4 , e ausente nos demais dedos; discos adesivos ausentes; extremidades das falanges terminais arredondadas; olhos dorso-laterais; presença de listras horizontais na região ventral da coxa Pseudis platensis

24a (23a). Membrana interdigital entre os artelhos I e II não se estendendo além do tubérculo subarticular do artelho I; distância olho-narina maior que o diâmetro do olho; discos adesivos em formato de " $T$ " Scinax 25

24b. Membrana interdigital dos artelhos I e II se estendendo para além do tubérculo subarticular (Figura 7h) do artelho I; discos adesivos não possuem formato de "T"

25a (24a) Presença de manchas amarelas na face posterior das coxas e na região inguinal em vida; focinho alongado em vista dorsal; CRC superior a $30 \mathrm{~mm}$ clado de $S$. ruber 26

25b CRC variando entre 20 e $30 \mathrm{~mm}$; focinho acuminado 27

26a. (25a) CRC entre 27 e 44 mm; dedo II maior que o dedo IV; dorso com manchas irregulares de coloração castanho escura; disco adesivo menor que o diâmetro do tímpano Scinax fuscovarius

26b. CRC entre 31 e 42 mm; dedo II com o mesmo tamanho do dedo IV; dorso com coloração homogênea; alguns indivíduos com manchas claras no dorso; largura do disco adesivo igual ao diâmetro do tímpano Scinax sp. (aff. similis)

27a. (25b) Região dorsal cinza escuro ou amarronzada em vida, com faixas interoculares largas; mancha esbranquiçada acompanhando a maxila, do lábio superior à margem anterior do olho; tímpano com diâmetro maior ou igual à metade do diâmetro do olho

Scinax berthae

27b. Faixa dorsal alaranjada se estendendo da ponta do focinho até a cloaca, emarginada por duas faixas dorso-laterais castanho-escuro em vida; sem faixa interocular; tímpano menor que a metade do diâmetro do olho; focinho acuminado Scinax fuscomarginatus 
28b. Porte médio a grande (CRC superior a $40 \mathrm{~mm}$ )

29a. (28a) Dorso com padrão de linhas estreitas e longitudinais, mas sem faixas longitudinais ou desenhos irregulares no dorso

29b. Dorso sem linhas, mas com padrão marmoreado ou com desenhos irregulares

30a. (29a) Em machos adultos CRC varia de 15 a $18 \mathrm{~mm}$; narinas na ponta do focinho; dentes vomerianos evidentes; dorso cinza ou amareloesverdeado; em vida a parte interna da coxa é bege, e nunca laranja; saco vocal transparente

D. sanborni

30b. CRC variando de 18 a $22 \mathrm{~mm}$; narinas na ponta do focinho, mas um pouco mais afastadas do focinho em relação a $D$. sanborni; dentes vomerianos reduzidos; em vida, dorso acinzentado ou bege, com o ventre das mãos, pés e coxas laranja claro, saco vocal amarelado ...

D. nanus

31a. (29b) Franja dérmica tarsal ausente; membranas interdigitais pouco desenvolvidas ou ausentes no membro anterior, não ultrapassando em comprimento o primeiro dedo 32

31b. Manchas dorsais com padrão marmoreado; franja dérmica tarsal presente (Figura 7c); membranas interdigitais bem desenvolvidas no membro anterior, ultrapassando o segundo dedo D. melanargyreus

32a. (31a) CRC variando de 20 a $27 \mathrm{~mm}$; região dorsal verde uniforme em vida; em animais fixados esta cor se modifica para violeta ou rosa..

D. elianeae

32b. Região dorsal castanho escuro em animais fixados, com faixas longitudinais (em alguns indivíduos, em formato de ampulheta) ao longo da região dorsal e faixas estreitas nos flancos; CRC variando entre 18 e $24 \mathrm{~mm}$ D. minutus

33a. (28b) Saco vocal único; pele lisa; glândulas parotóides ausentes Hypsiboas 34

33b. Presença de sacos vocais duplos; pele rugosa; membros anteriores robustos; glândulas parotóides evidentes na região occipital e escapular; ventre de coloração creme, com manchas brancas em vida; disco do III dedo maior do que o diâmetro do tímpano

Trachycephalus typhonius

34a. (33a) Porte mediano (CRC inferior a $75 \mathrm{~mm}$ ); tímpano pequeno com aproximadamente $4 \mathrm{~mm}$ de diâmetro 35

34b. Porte grande (CRC superior a $80 \mathrm{~mm}$ ), com aspecto robusto; prepólex bastante desenvolvido; na maioria dos indivíduos está presente uma linha escura estreita longitudinal no dorso; tímpano grande com aproximadamente $7 \mathrm{~mm}$ de diâmetro H. faber

35a. (34a) Região dorsal sem aspecto marmoreado, com manchas irregulares; presença de listras ou manchas nos flancos; membrana interdigital pouco desenvolvida nos membros anteriores. grupo de H. albopunctatus 36

35b. Região dorsal com aspecto marmoreado; coxa (Figura 7b) e flancos com listras verticais escuras contínuas entre coxa e flanco; membranas interdigitais bastante desenvolvidas

H. lundii

36a. (35a) Manchas amarelas arredondadas na face posterior da coxa, em animais fixados esta cor muda para branca; CRC variando entre 41 e $59 \mathrm{~mm}$; região dorsal com manchas transversais H. albopunctatus

36b. Faixas escuras irregulares na face posterior da coxa; CRC variando entre 59 e $76 \mathrm{~mm}$ H. raniceps 